\title{
Study of fetomaternal outcome in instrumental vaginal deliveries at a tertiary teaching hospital
}

\author{
Anurag A Sonawane, Shrinivas N Gadappa, Rupali A Gaikwad
}

\begin{abstract}
Corresponding author: Dr. Anurag A Sonawane, Associate Professor, Department of Obstetrics and Gynecology, Government Medical College, Aurangabad, Maharashtra, India; Email : anurag0344@gmail.com
\end{abstract}

Distributed under Attribution-Non Commercial - Share Alike 4.0 International (CC BY-NC-SA 4.0)

\begin{abstract}
Objectives: To study the maternal and neonatal outcome in patients undergoing instrumental vaginal delivery (vacuum \& forceps delivery) at a tertiary care teaching hospital. Methods: This retrospective study was carried out in patients undergoing instrumental vaginal delivery during the study period. Results: In present study total 266 patients were included. $1.39 \%$ instrumental vaginal deliveries were noted. Most common age group in present study was 2125 years in both groups (39\%-vacuum, $41 \%$ - forceps). Instrumental vaginal deliveries were common in patients with 37-40 weeks of gestation. In present study most common indication for Instrumental vaginal delivery (vacuum \& forceps) was delayed second stage (32\%) followed by fetal distress (26\%) \& medical disorders (18 \%). In present study, 3 fresh still births and 3 early neonatal deaths were noted, common indication was fetal distress in second stage of labour. We noted cervical lacerations (15\%), PPH requiring blood transfusion (13\%), vaginal lacerations (10\%), extension of episiotomy $(5 \%) \&$ perineal injuries $(2 \%)$ as maternal complications. Neonatal jaundice was most common neonatal complication in present study ( $9 \%$ - vacuum, $15 \%$ - forceps). Conclusion: Instrumental vaginal delivery remains useful procedure if applied judiciously by a trained obstetrician. It helps to improve neonatal and maternal outcome, also helps to reduce caesarean delivery rate.
\end{abstract}

Keywords: Instrumental vaginal delivery, forceps delivery, vacuum delivery, maternal and fetal

outcome.

Instrumental vaginal delivery includes either vacuum extraction or forceps extraction for fetal head delivery, is an important component of obstetric care. Birth rates by caesarean in the recent years have risen throughout the world. Instrumental vaginal deliveries are important for decreasing birth rates by caesarean and related morbidities. ${ }^{1}$

The commonest indications for instrumental vaginal delivery are prolonged second stage of labour, suspicion of immediate or potential fetal compromise and shortening of the second stage of labour for maternal benefit. ${ }^{2}$ Malpresentation, incompletely dilated cervix, unengaged fetal head, cephalopelvic disproportion and fetal clotting disorder are some of the absolute contraindications.

With increasing patient awareness and medico-legal issues regarding complications to mother and fetus secondary to instrumental delivery, obstetricians at present prefer caesarean delivery. There is also a concern that there may be a significantly increased risk of third/fourth degree tears, severe maternal morbidity and death, perinatal mortality and neonatal mortality in women with instrumental vaginal birth compared with normal birth. ${ }^{3}$

The goal of instrumental vaginal delivery is to assist the

Received: $10^{\text {th }}$ April 2020, Peer review completed: $20^{\text {th }}$ May 2020, Accepted: $31^{\text {st }}$ May 2020.

Sonawane AA, Gadappa SN, Gaikwad RA. Study of fetomaternal outcome in instrumental vaginal deliveries at a tertiary teaching hospital. The New Indian Journal of OBGYN. 2021; 7(2): 172-76. 
The New Indian Journal of OBGYN. 2021 (January-June);7(2)

spontaneous vaginal birth providing minimum maternal and neonatal morbidity. High level of clinical and technical skills and therefore, adequate training is necessary for the use of both instruments. ${ }^{4}$ The safety and success of procedure depends on operator skill, proper timing, and justified indications. ${ }^{5}$ The present study was under taken to evaluate maternal and neonatal outcome with use of vacuum and forceps at a tertiary care center.

\section{Material and methods}

This retrospective, cross sectional study was carried out in department of Obstetric \& Gynaecology, Government medical college, Aurangabad. Study duration was from Jan 2019 - Dec 2019. Institutional ethical committee approval was taken for the present study. Patients undergoing instrumental vaginal delivery in study period were included in the present study. Patient records were reviewed for study purpose. All records were kept as confidential.

In our institute, forcep deliveries were performed by application of the short-curved outlet forceps. Vacuum deliveries were performed by application of silastic cups. In all cases of instrumental vaginal delivery, immediately after the delivery of the baby, active management of third stage of labour along with prophylactic $600 \mathrm{mcg}$ misoprostol was given. After delivery of placenta, a compulsory per speculum examination at the labour table to look for cervicovaginal injuries was conducted. All the cases were given intravenous antibiotics for three days. These patients were discharged on day 4 .

Age, gravida, obstetric history, progress of labour, laboratory investigations, accompanying medical/ obstetric conditions were noted. The indication, type of instrumental vaginal delivery, post-delivery per speculum examination findings (cervical lacerations, vaginal laceration, perineal tear, episiotomy extensions or periurethral tear), other maternal complications (post-partum haemorrhage, cervico-vaginal exploration under anaesthesia, blood transfusion, etc) were noted. Newborn outcome in terms of APGAR scoring at $1 \mathrm{~min}$ and 5 mins, convulsions, instrumental injuries or complications (cephalhematomas, caput succedaneum, NICU admissions, jaundice, neonatal sepsis) were noted. All findings were noted in Microsoft excel sheet. Statistical analysis was done using descriptive statistics.

\section{Results}

In present study total 266 patients were included. During study period total 19323 deliveries were conducted at our hospital. Out of these 13937 (72.12\%) were vaginal, 5120 (26.49\%) were caesarean deliveries and $266(1.39 \%$, out of which $1.01 \%$ - vacuum, $0.38 \%$ - forceps) were instrumental vaginal deliveries. As seen in table 1, most common age group in present study was 21-25 years in both

Table 1: Demographic profile

\begin{tabular}{|c|c|c|}
\hline Parameters & Vacuum $(\%, n=195)$ & Forceps $(\%, n=71)$ \\
\hline \multicolumn{3}{|l|}{ Maternal Age } \\
\hline$\leq 20$ years & $31(16 \%)$ & $13(18 \%)$ \\
\hline $21-25$ years & $76(39 \%)$ & $29(41 \%)$ \\
\hline $26-30$ years & $53(27 \%)$ & $14(20 \%)$ \\
\hline $31-35$ years & $26(13 \%)$ & $11(15 \%)$ \\
\hline$>35$ years & $9(5 \%)$ & $4(6 \%)$ \\
\hline \multicolumn{3}{|c|}{ Previous vaginal deliveries } \\
\hline 0 & $104(53 \%)$ & $51(72 \%)$ \\
\hline $1-2$ & $57(29 \%)$ & $16(23 \%)$ \\
\hline$>2$ & $34(17 \%)$ & $4(6 \%)$ \\
\hline \multicolumn{3}{|c|}{ Gestational Age } \\
\hline$<37$ weeks & $11(6 \%)$ & $6(8 \%)$ \\
\hline $37-40$ weeks & $121(62 \%)$ & $38(54 \%)$ \\
\hline$>40$ weeks & $63(32 \%)$ & $27(38 \%)$ \\
\hline
\end{tabular}

groups (39 \%-vacuum, $41 \%$ - forceps), followed by $26-30$ years age group (27\% - vacuum, $20 \%$ - forceps). Instrumental vaginal deliveries were common in nulliparous patients ( $53 \%$-vacuum, $72 \%$ - forceps). Instrumental vaginal deliveries were common in patients with 37-40 weeks of gestation (54\%- vacuum, 54\%- forceps), followed by

Table 2: Indications for instrumental vaginal delivery

\begin{tabular}{|c|c|c|c|}
\hline Indications $(n=266)$ & No. of patients (\%) & Vacuum $(\%, n=195)$ & Forceps $(\%, n=71)$ \\
\hline Delayed second stage of labor & $84(32 \%)$ & $68(35 \%)$ & $16(23 \%)$ \\
\hline \multicolumn{4}{|c|}{ Elective shortening of second stage of labor } \\
\hline Fetal distress & $68(26 \%)$ & $52(27 \%)$ & $16(23 \%)$ \\
\hline Medical disorders & $49(18 \%)$ & $38(19 \%)$ & $11(15 \%)$ \\
\hline Severe pre-eclampsia/eclampsia & $19(7 \%)$ & $14(7 \%)$ & $5(7 \%)$ \\
\hline Preterm delivery & $17(6 \%)$ & $3(2 \%)$ & $14(20 \%)$ \\
\hline Abruptio placenta & $12(5 \%)$ & $9(5 \%)$ & $3(4 \%)$ \\
\hline Twin gestation & $11(4 \%)$ & $7(4 \%)$ & $4(6 \%)$ \\
\hline Cord prolapse & $6(2 \%)$ & $4(2 \%)$ & $2(3 \%)$ \\
\hline
\end{tabular}

patients with $>40$ weeks gestation (32\% - vacuum, 38\% forceps).

As seen in table 2, most common indication for Instrumental vaginal delivery (vacuum \& forceps) was delayed second stage (32\%) followed by fetal distress (26\%) and medical disorders (18\%).

As seen in table 3, 2.6-3 kg birth weight group was most common (50\%-vacuum, 44\%- forceps), followed by 3.1-3.5 $\mathrm{kg}$ group (37\%- vacuum, 38\%- forceps) \& $>3.5 \mathrm{~kg}$ weight group (13\%-vacuum, 18\%- forceps). Most babies had more than 7 APGAR at $1 \mathrm{~min}$ (88\%-vacuum, 77\%- forceps) \& 
The New Indian Journal of OBGYN. 2021 (January-June);7(2)

APGAR at 5 mins (94\%-vacuum, 89\%-forceps). In present study, 3 fresh still births and 3 early neonatal deaths were noted, common indication was fetal distress in second stage of labour.

\begin{tabular}{|c|c|c|}
\hline Birth weight & Vacuum $(\%, n=195)$ & Forceps $(\%, n=71)$ \\
\hline$<2 \mathrm{~kg}$ & 0 & $2(3 \%)$ \\
\hline $2-2.5 \mathrm{~kg}$ & $3(2 \%)$ & $12(17 \%)$ \\
\hline $2.6-3 \mathrm{~kg}$ & $98(50 \%)$ & $31(44 \%)$ \\
\hline $3.1-3.5 \mathrm{~kg}$ & $72(37 \%)$ & $27(38 \%)$ \\
\hline$>3.5 \mathrm{~kg}$ & $25(13 \%)$ & $13(18 \%)$ \\
\hline \multicolumn{3}{|c|}{ APGAR at $1 \mathrm{~min}$} \\
\hline$<3$ & $2(1 \%)$ & $5(7 \%)$ \\
\hline $4-7$ & $21(11 \%)$ & $11(15 \%)$ \\
\hline $7-10$ & $172(88 \%)$ & $55(77 \%)$ \\
\hline \multicolumn{3}{|c|}{ APGAR after 5 min } \\
\hline$<3$ & $2(1 \%)$ & $4(6 \%)$ \\
\hline $4-7$ & $9(5 \%)$ & $4(6 \%)$ \\
\hline $7-10$ & $184(94 \%)$ & $63(89 \%)$ \\
\hline
\end{tabular}

As seen in table 4, cervical lacerations (15\%), PPH requiring blood transfusion (13\%), vaginal lacerations $(10 \%)$, extension of episiotomy (5\%) and perineal injuries (2\%) as maternal complications in vacuum delivery. Similarly, in forceps delivery we noted PPH requiring blood transfusion (18\%), cervical lacerations (14\%), vaginal lacerations $(13 \%)$, extension of episiotomy $(8 \%)$, perineal injuries (2\%), vulval hematoma (1\%) and colporrhexis (1\%). During study period we noted no near miss maternal mortality or maternal mortality in patients with instrumental vaginal delivery.

Neonatal jaundice was most common neonatal complication in present study ( $9 \%$ - vacuum, $15 \%$ forceps). Cephalhematoma (4\%), scalp injuries (3\%) and neonatal convulsions $(2 \%)$ were other complications noted with vacuum delivery. Facial marks and abrasions (8\%), scalp injuries $(3 \%) \&$ neonatal convulsions $(3 \%)$ were noted with forceps delivery.

Table 4: Complications

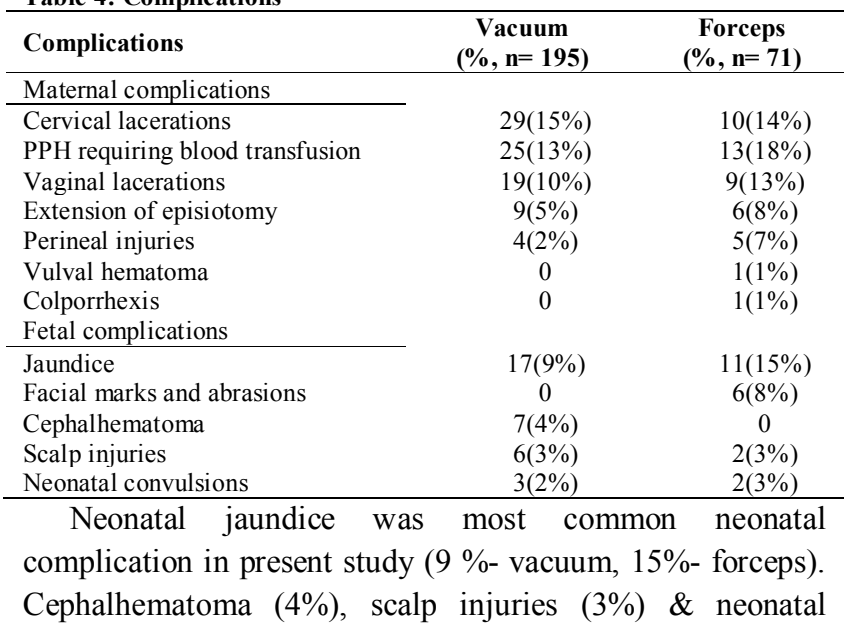

convulsions (2\%) were other complications noted with vacuum delivery. Facial marks and abrasions (8\%), scalp injuries (3\%) \& neonatal convulsions (3\%) were noted with forceps delivery.

\section{Discussion}

Incidence of instrumental vaginal deliveries was $1.39 \%$ in present study. Most common indication for instrumental vaginal delivery (vacuum $\&$ forceps) was delayed second stage $(32 \%)$ followed by fetal distress $(26 \%)$ \& medical disorders (18\%). Cervical lacerations (15\%), PPH requiring blood transfusion (13\%), vaginal lacerations $(10 \%)$ were the maternal complications. During study period we noted no near miss maternal mortality in patients with instrumental vaginal delivery. In present study, 3 fresh still births and 3 early neonatal deaths were noted, common indication was fetal distress in second stage of labour. Neonatal jaundice was most common neonatal complication in present study ( $9 \%$ - vacuum, $15 \%$ - forceps).

Instrumental vaginal delivery (IVD) is a key element of essential obstetric care, and significantly reduces maternal and newborn morbidity and mortality especially in resource poor countries. ${ }^{6}$ In response to the growing number of caesarean deliveries and the morbidities associated with them the instrumental vaginal delivery is a great tool to prevent the primary as well as repeat caesarean delivery.

Over the years, there has been a gradual shift from the use of forceps to the vacuum. This may be because the vacuum is safer, the skill is more easily acquired, and it has an in-built safety mechanism. ${ }^{5}$ On the contrary, application of forceps is technically more difficult and requires time to acquire the skill. The rate of IVD was fairly constant during the period under review despite the rising CS rate unlike in developed countries where the rates are declining due to litigations. $^{7}$

During study period $72.12 \%$ were vaginal deliveries, $26.49 \%$ were caesarean deliveries \& $1.39 \%(1.01 \%$ vacuum, $0.38 \%$ - forcep) were instrumental vaginal deliveries in our hospital. In previous study from same institute the incidence of instrumental vaginal delivery was $1.09 \%$. A tertiary teaching hospital in Pondicherry, India during five year noted the rate of instrumental deliveries ranges from $6.1 \%$ to $9.8 \%{ }^{9}$ The incidence of instrumental vaginal delivery in the United States is $4.5 \%$ and that in United Kingdom is between 10\%-15\%. Our Instrumental vaginal deliveries rate is also lower than the recommended rate of $8.5 \%$ by the Royal College of Obstetricians and 
Gynaecologists (RCOG) and much lower than the rates in developed countries. ${ }^{10}$

Most common age group in present study was 21-25 years in both groups (39 \%- vacuum, 41\%- forceps), followed by 26-30 years age group ( $27 \%$ - vacuum, $20 \%$ forceps). Another study noted similar findings as 20 to 25 years $(53.17 \%)$ followed by 25 to 30 years. $(34.78 \%){ }^{8}$ Majority of the vacuum procedures were carried out at term, which is the acceptable practice. Most authorities consider it a contraindication if the gestational age is less than 34 weeks, due to increased risk of cephalhaematoma. ${ }^{11}$

The indications for IVD include delayed second stage of labour, poor progress of labour due to maternal fatigue or exhaustion, and fetal distress or non-reassuring fetal heart rate tracing the second stage of labour. Other maternal indications include medical conditions such as cardiac diseases, especially New York Heart Association (NYHA) class III/IV, or neurologic diseases, including uncorrected intra-cerebral vascular malformations as well as hypertensive crisis, myasthenia gravis, spinal cord injury patients at risk of autonomic dysreflexia, and proliferative retinopathy. ${ }^{7}$

In present study most common indication for Instrumental vaginal delivery (vacuum \& forceps) was delayed second stage (32\%) followed by fetal distress (26 \%) \& medical disorders (18\%). Prolonged or complicated second stage of labour is associated with potentially serious maternal complications and deaths as well as stillbirths and neonatal morbidity and mortality. ${ }^{12}$ In another Indian study, cutting short of 2nd stage of labor (i.e., where prolonged bearing down is detrimental for the mother in cases of hypertension, heart disease etc.) was the chief indication followed by prolonged 2 nd stage. ${ }^{13}$

We noted cervical lacerations (15\%), PPH requiring blood transfusion (13\%), vaginal lacerations $(10 \%)$, extension of episiotomy (5\%) \& perineal injuries $(2 \%)$ as maternal complications in vacuum delivery. Similarly, in forceps delivery maternal complications were PPH requiring blood transfusion (18\%), cervical lacerations (14\%), vaginal lacerations $(13 \%)$, extension of episiotomy $(8 \%)$, perineal injuries (2\%), vulval hematoma (1\%) \& colporrhexis $(1 \%)$. While use of forceps is associated with increased maternal perineal trauma with need for analgesia and neonatal facial injury, cephalhematoma and subgaleal haemorrhage are associated with vacuum birth.

In the review of over 50000 vaginal deliveries at the University of Miami, the rate of $3 \mathrm{rd} / 4$ th perineal lacerations were significantly higher in forceps $(20 \%)$ and vacuum
$(10 \%)$ as compared to the Spontaneous vaginal delivery. ${ }^{14}$ Biru et $\mathrm{al}^{15}$ noted that mother who had forceps delivery was 3.4 times more likely to develop maternal complication than mother who had vacuum delivery.

Instrumental deliveries require additional vaginal examinations, higher rates of vaginal lacerations, routine bladder catheterisation, insertion of instruments, all are known risk factor for endometritis and febrile morbidity. Insertion of instruments and contamination is also assumed to be one of the risk of postpartum infection because of difficulties in adhering to aseptic practices during delivery. ${ }^{2}$

Neonatal jaundice was the most common neonatal complication in present study (9\%-vacuum, $15 \%$ - forceps). Cephalhematoma (4\%) was noted with vacuum delivery while facial marks and abrasions (8\%) were noted with forceps delivery. Neonates delivered with forceps have more facial injuries, whereas those delivered with vacuum have more cephalohematomas. Other neonatal complications observed are asphyxia, cerebral palsy and neonatal death. ${ }^{16}$

Presently many obstetricians prefer caesarean delivery due to a concern that there may be a significantly increased risk of third/fourth degree tears, severe maternal morbidity and mortality, perinatal mortality and neonatal mortality in women with instrumental vaginal birth compared with normal/caesarean birth. $^{3}$ In present study with 266 instrumental vaginal deliveries we did not found any significant maternal \& neonatal mortality / morbidity. Instrumental vaginal birth should be encouraged to improve maternal \& neonatal outcome. A prospective long duration study could help to understand long term complications of instrumental vaginal delivery in near future.

\section{Conclusion}

Though instrumental vaginal delivery appears to cause complications in both the mothers and babies but most of all these complications are minor in nature. Instrumental vaginal delivery remains useful procedures if applied judiciously by a trained obstetrician. It helps to improve neonatal and maternal outcome, also helps to reduce caesarean delivery rate.

\section{Conflict of interest: None. Disclaimer: Nil.}

\section{References}

1. Spongy CY, Berghella V, Wenstrom KD. Preventing the first caesarean delivery. Obstet Gynecol. 2012; 120: 1181-93. 
The New Indian Journal of OBGYN. 2021 (January-June);7(2)

2. Liabsuetrakul T, Choobun T, Peeyananjarassri K, Islam QM. Antibiotic prophylaxis for operative vaginal delivery. Cochrane Database of Systematic Reviews. 2017; 8: CD004455.

3. Lumbiganon P, Laopaiboon M, Gülmezoglu M, Souza JP, Taneepanichkul S, Ruyan P, et al. Method of delivery and pregnancy outcomes in Asia: the WHO global survey on maternal and perinatal health 2007-08. Lancet. 2010; 375: 490-9.

4. Demissie K, Rhoads GG, Smulian JC, Balasubramanian BA, Gandhi K, Joseph KS, et al. Operative vaginal delivery and neonatal and infant adverse outcomes: population based retrospective analysis. BMJ. 2004; 329(7465): 24-9

5. O'Mahony F, Hofmeyr GJ, Menon V. Choice of instruments for assisted vaginal delivery. Cochrane Database of Systematic Reviews. 2010 Nov 10; 11: CD005455.

6. Adaji SE, Ameh CA. Operative Vaginal Deliveries in Contemporary Obstetric Practice, from Preconception to postpartum. 2012. Available from: https://www.intechopen.com/books/from-preconceptionto-postpartum/ operative- vaginal-deliveries-incontemporary-obstetric-practise

7. Royal College of Obstetricians and Gynaecologists. Operative vaginal delivery. RCOG Green top Guideline No. 26. London: RCOG; 2011.

8. Khan Q, Bhingare PE, Gadappa SN, Kamath SS. Maternal and perinatal outcome in instrumental vaginal delivery. MedPulse - International Journal of Gynaecology. July 2017; 3(1): 19-22.

9. Dhodapkar SB, Chauhan RC. Trends of instrumental deliveries at a tertiary care teaching hospital in Puducherry. Indian Journal of applied research. 2015; 5 (7): 513-5.

10. Ameh CA, Weeks AD. The Role of Instrumental Vaginal delivery in low resource settings; BJOG. 2009; 116(1): 22-5.
11. Odoi AT, Opare - Addo HS. Operative Vaginal Delivery, Forceps Delivery and Vacuum Extraction. In: Kwawukume EY, Ekele BA, Danso KA, Emuveyan EE, editors. Comprehensive Obstetrics in the Tropics. Accra: Asante and Hittscher Printing Press Limited; 2015. pp 422-34.

12. Altman MR, Lydon-Rochelle MT. Prolonged second stage of labor and risk of adverse maternal and perinatal outcomes: a systematic review. Birth. 2006; 33(4): $315-22$.

13. Singh A, Rathore P. A comparative study of fetomaternal outcome in instrumental vaginal delivery. J Obstet Gynaecol India. 2011; 61: 663-6.

14. Angoli R, Gomez MO, Centuaria G, Sullivan OMJ. Severe Perineal lacerations during vaginal delivery; The University of Miami Experiences. Am J Obstet Gynecol. 2008;182:1083-5.

15. Biru S, Addisu D, Kassa S, Animen S. Maternal complication related to instrumental delivery at Felege Hiwot Specialized Hospital, Northwest Ethiopia: a retrospective cross sectional study. BMC Res Notes. 2019; 12: 482.

\footnotetext{
Anurag A Sonawane ${ }^{1}$, Shrinivas N Gadappa ${ }^{2}$, Rupali A Gaikwad $^{3}$

${ }^{1}$ Associate Professor, Department of Obstetrics and Gynecology, Government Medical College, Aurangabad, Maharashtra, India; ${ }^{2}$ Professor \& Head of department, Department of Obstetrics and Gynecology, Government Medical College, Aurangabad, Maharashtra, India; ${ }^{3}$ Assistant Professor, Department of Obstetrics and Gynecology, Government Medical College, Aurangabad, Maharashtra, India.
} 